\title{
FEUERBACH: SUPERACIÓN DE LA RELIGIÓN COMO FORMA DE AUTOCONCIENCIA HUMANA
}

\section{FEUERBACH: OVERCOMING OF RELIGION AS A FORM OF HUMAN SELF-CONSCIOUSNESS}

\author{
Raúl FERNÁNDEZ-COBOS* \\ Universidad de Cantabria
}

Resumen: La crítica de Feuerbach concibe el fenómeno religioso como una manifestación efectiva de la autoconciencia humana. Partiendo de este supuesto, el presente artículo tiene como objeto contextualizar, a la luz de un desarrollo histórico, el humanismo propuesto por el autor como siguiente estadio del proceso de autoconocimiento humano. Dicha propuesta implicaría necesariamente el reconocimiento de los mecanismos de enajenación implícitos en la religión y, en definitiva, su superación. Al desembarazarse de las especulaciones propias de la fe, la reducción de la teología a la antropología despojaría a la realidad de todo elemento sobrenatural y supondría un avance significativo en pos de la plenitud humana.

Palabras Clave: Ateísmo; conciencia; Feuerbach; historicidad; humanismo; religión.

AвSTRACt: Religion is conceived as an effective manifestation of human self-consciousness in Feuerbach's critique. Based on this assumption, the present paper aims to contextualize his humanist approach within a historical framework in which it is seen as the next step in the development of human self-knowledge. Such a proposal would necessarily imply the recognition of the alienation mechanisms inherent in religion, and, in essence, overcoming it. Getting rid of speculative faith, the reduction of theology to anthropology would dismiss the supernatural elements from the conception of reality and this would represent a substantial step forward on the way to human plenitude.

KeYwords: Atheism; consciousness; Feuerbach; historicity; humanism; religion.

\footnotetext{
* Profesor Ayudante Doctor en el Departamento de Matemáticas, Estadística y Computación de la Universidad de Cantabria. Correo electrónico: rfdz.cobos@gmail.com
} 


\section{Introducción}

Lejos de constituir una aportación meramente destructiva, la crítica de la religión que Feuerbach hace en La esencia del cristianismo forma parte de una propuesta de superación en términos humanistas, una reivindicación de la dignidad humana ${ }^{1}$. En ella, «la pregunta por la existencia de Dios tiene sentido por su repercusión en la existencia del ser humano» (García-Valdecasas y Belmonte, 2018: 396). En el prólogo de su edición de la obra por excelencia de Feuerbach, Manuel Cabada Castro alude a esta cuestión refiriéndose al ateísmo de éste como específico: «Es al mismo tiempo entusiasmo por el mundo, fe absoluta en la humanidad» (Feuerbach, 2013: 26). Se trata, por tanto, de un ateísmo positivo (cf. Piñón, 2014: 201). El mismo Feuerbach trata de zanjar esta cuestión en el prólogo de la primera edición de sus Obras completas:

Quien no sabe decir de mí sino que soy ateo, no sabe nada de mí (...) Yo niego a Dios. Esto quiere decir en mi caso: yo niego la negación del hombre (...) La cuestión del ser o no ser de Dios es en mi caso únicamente la cuestión del ser o no ser del hombre (citado en Feuerbach, 2013: 21).

La negación del sujeto no implica la negación de sus predicados; unos predicados que, en el pensamiento de Feuerbach, no son divinos por el hecho de ser asociados a Dios sino que, por el contrario, son asociados a éste porque son perfectos y verdaderos por sí mismos. Remiten, en último término, a la esencia del género, que no es más que el objeto de la autoconciencia del ser humano. El misterio de la religión se desvela sin elementos sobrenaturales, pues su contenido es completamente humano. La teología se reduce a la antropología.

Epistemológicamente, estos planteamientos posicionan al Feuerbach de la época en un realismo sensualista que, aunque no niega el pensamiento, lo complementa con la experiencia (García-Valdecasas y Belmonte, 2018: 398). Aunque favorece la experiencia sensible frente a la especulación idealista, en ningún caso reduce al ser humano en el plano ontológico a su corporeidad ${ }^{2}$. Se trata, por tanto, de un materialismo con espíritu (García-Valdecasas y Belmonte, 2018:

\footnotetext{
${ }^{1}$ De ahí que el propio Feuerbach califique su filosofía como "terapéutica", puesto que desmonta la teología para reafirmar al ser humano (Gil, 2016: 517).

2 «El materialista carente de espíritu dice: "El hombre se distingue del animal solo por la conciencia, es un animal dotado de conciencia", olvidando de ese modo que en un ser que se despierta a la conciencia se produce un cambio cualitativo del ser total» (Feuerbach, 2013: 54).
} 
398) -o, si se prefiere, un realismo naturalista (Piñón, 2014: 205)-; en el que se concibe el espíritu como el producto más elevado de la materia (Piñón, 2014: 195). En sus "Tesis sobre Feuerbach" (recogidas en Marx y Engels, 1974: 665668), Marx lo concibe como un materialismo contemplativo, en la medida en que aborda lo sensorial desde la teoría, no como actividad práctica; Feuerbach no habría dejado atrás definitivamente a Hegel, para quien «la relación [del hombre] con el mundo es concomitante siempre» (Küng, 1979: 211). Pero en cualquier caso, no hay que olvidar que «la realidad fundamentante del conocimiento en Feuerbach no es solamente la realidad objetiva o cósica, sino también y de manera principal (e incluso como mediadora de la anterior), la realidad personal» (Cabada, 1980: 77).

Esta etapa del pensamiento de Feuerbach suele concebirse como parte de un proceso de evolución intelectual marcado por su propia biografía ( $c f$. Amengual, 1980: 26-32). Dado el carácter asistemático e inconstante de su obra, ésta ha sido susceptible de ser dividida en diferentes periodos cuya definición no siempre coincide de unos autores a otros ( $c f$. Gil, 2016: 513). El proceso parte de su idealismo inicial, afín a Hegel, y termina en el materialismo del último Feuerbach. Tras doctorarse, en 1828, con una tesis de planteamientos hegelianos, el autor comienza a desviarse progresivamente de Hegel. Durante la década siguiente, se gesta en él un distanciamiento de la filosofía especulativa de su referente académico para centrarse en la realidad concreta ( $c f$. Cabada, 1975: 10), que se cristaliza en «una reducción ontológica progresiva de la realidad de la Infinitud hasta convertirla finalmente en mera indefinidad de la razón humana individual o del género humano en cuanto tal» (Cabada, 1975: 95). En 1841 publica La esencia del cristianismo, que supone la ruptura definitiva con su pasado hegeliano ${ }^{3}$. En esta obra, Feuerbach racionaliza la teología (Cabada, 1975: 19) llevando a cabo una inversión del pensamiento de Hegel en los siguientes términos:

Si Hegel afirma que el ser humano es un momento de la conciencia de Dios, Feuerbach subraya lo contrario, esto es, que Dios es un momento de la conciencia del ser humano, pero la conciencia del ser humano no es la autoconciencia de Dios (García-Valdecasas y Belmonte, 2018: 398-399).

\footnotetext{
${ }^{3}$ El propio Feuerbach describe su evolución con estas palabras: «Dios fue mi primer pensamiento; la razón, el segundo, y el hombre, mi tercero y último pensamiento» (citado en Cabada, 2010: 292).
} 
El presente artículo tiene como objeto la elucidación del proceso que lleva a Feuerbach a postular su religión del amor como superación del cristianismo. Un hito que, a su juicio, marcaría un punto de inflexión en la historia de la humanidad. En primer lugar, se ahonda en los mecanismos psicológicos que propone como causas del fenómeno religioso. A continuación, se repasa la concepción histórica de la religión defendida por Feuerbach. En La esencia del cristianismo, el autor esboza el itinerario, desde el politeísmo pagano hasta las religiones monoteístas de su contemporaneidad, centrándose especialmente en la evolución del propio cristianismo. Este análisis se complementa en La esencia de la religión, publicada en 1846, donde Feuerbach profundiza en las motivaciones psicológicas que provocan las primeras manifestaciones religiosas. En esta obra, la naturaleza se erige en la subjetividad humana como una entidad externa, desconocida y hostil; es la fuente de frustración que actúa como detonante del proceso de enajenación que da lugar a la religión. Si bien el propio Feuerbach defiende que esta nueva caracterización no solo no entra en conflicto con lo expuesto en La esencia del cristianismo, sino que además contribuye a llenar una laguna que había quedado sin explicar (Cabada, 2010: 298); a muchos de sus críticos no se les ha pasado por alto que el nuevo punto de vista rompe con el antropocentrismo subjetivista que justifica el fenómeno religioso exclusivamente a partir de la autorreferencia de lo humano para incorporar un elemento externo y material que condiciona y justifica los deseos del ser humano ${ }^{4}$.

Sin ánimo de minusvalorar este cambio ideológico, la reconstrucción que se ofrece de la evolución histórica de la religión incorpora elementos de ambas obras con la intención de describir el proceso de la manera más completa posible. Finalmente, se expone la propuesta humanista que Feuerbach considera necesaria para superar el cristianismo y acercarse más a la plenitud humana, basada en la preeminencia otorgada a las relaciones sociales entre humanos, especial y fundamentalmente al amor.

\section{Dios como objetivación de la esencia humana}

Feuerbach sostiene que la diferencia más comúnmente aducida entre humanos y otros animales es que los primeros tienen conciencia. Sin embargo, la noción de conciencia que maneja trasciende la mera percepción de sí mismo, es decir, la capacidad de discernir entre el propio sujeto y un entorno exterior con

${ }^{4}$ Bajo la nueva perspectiva, «la antropología es integrada a la fisiología» (Piñón, 2014: 202). 
el que puede interactuar. La conciencia, en este caso, marca la diferencia por ser una percepción colectiva, a saber: la capacidad de abstracción, a partir de la aprehensión del individuo, de las cualidades del conjunto al que pertenece, concebido como clase. Pues la humanidad -el género- en La esencia del cristianismo se concibe como esencia. "La conciencia, en sentido estricto, solo existe allí donde un ser tiene como objeto su propio género, su propia esencialidad» (Feuerbach, 2013: 53) $)^{5}$. La percepción del género es, asimismo, responsable de la socialización humana y de su capacidad empática, deduce la segunda persona a partir del propio individuo y su adscripción a la especie:

El hombre es, al mismo tiempo, para sí mismo el yo y el tú; él puede ponerse en el lugar del otro, precisamente porque su objeto no es solamente su individualidad, sino también su especie genérica, su esencia (Feuerbach, 2013: 54).

Además, el autor advierte en esta actitud un mecanismo psicológico que será la base de su concepción de la religión. Una vez que el género es representado como objeto, el ser humano procede con lo demás de forma análoga; de tal modo que la conciencia, entendida como objetivación de la especie, se erige como condición no solo necesaria sino también suficiente para la elaboración y el manejo conceptuales. «Solo un ser que tiene como objeto su propio género, su esencialidad, puede convertir en objeto otras cosas, otros seres, según su naturaleza esencial» (Feuerbach, 2013: 53). La objetivación, por tanto, está supeditada a la esencia del género, de forma que éste es la medida, la referencia de toda representación. Con ello, el autor no niega la existencia objetiva del mundo, pues no se trata de una pronunciación ontológica, como se deduce de las innumerables alusiones a la naturaleza en La esencia del cristianismo -y mucho más claramente en La esencia de la religión ${ }^{6}$ - sino epistemológica. En consecuencia, «conocer es siempre proyectar» (García-Valdecasas y Belmonte, 2018: 404). Y asimismo, la

\footnotetext{
${ }^{5}$ Implícitamente, se asume la unidad psíquica de la humanidad por la que se pronunciaron en el siglo XIX padres de la antropología moderna como Edward Tylor, James Frazer o Lewis Henry Morgan.

${ }^{6}$ «La naturaleza está comprendida solo en sí misma (...) ella es la única en la cual sigue siendo válida la diferencia entre lo que una cosa es en sí y lo que es para nosotros; ella es la única en la que ni estará permitido ni se podrá aplicar ninguna "norma humana", aunque comparemos y describamos sus fenómenos con fenómenos humanos análogos y, para que se nos haga inteligible, le apliquemos en general términos y conceptos como "orden", "fin", "ley", y debamos hacerlo en conformidad con la naturaleza de nuestro lenguaje, el cual solo está fundado en la apariencia subjetiva de las cosas» (Feuerbach, 2008: 87).
} 
esencia humana impone límites a nuestra capacidad de representación; pues «el hombre no puede ir más allá de su verdadera esencia» (Feuerbach, 2013: 62).

\subsection{La esencia humana}

El género se concibe necesariamente a partir de aquellas funciones que el individuo puede desarrollar con independencia de otros, pues la esencia se fundamenta en una autorreferencia ${ }^{7}$. Para Feuerbach, estas facultades son la razón, la voluntad y el amor: «son perfecciones, son facultades supremas, constituyen la esencia absoluta del hombre en cuanto hombre y el fin de su existencia» (Feuerbach, 2013: 55). Dichas determinaciones se fundamentan por sí mismas. Así, el fin del amor es el amor mismo, el fin de la razón es la propia razón y el fin de la voluntad es la libertad de querer una cosa y no otra. «La razón existe, porque solo la existencia de la razón es razonable, porque si no existiera la razón, no existiría la conciencia, todo sería nada, el ser sería igual al no ser» (Feuerbach, 2013: 93). Pero, asimismo, el ser es necesario porque: «si no existiera algo, existiría la nada" (Feuerbach, 2013: 93). Todo aquello que no necesita elementos externos para justificarse se considera divino y, por tanto, verdadero y perfecto; no ha de verse como un predicado independiente del sujeto, sino que determina el propio ser, pues el ser humano no sería humano sin ello. Estas facultades, juntas, constituyen la esencia del género; son el género. De esta manera, la especie se convierte en el objeto del ser humano; «sin objeto, el hombre es una nada» (Feuerbach, 2013: 56). Se trata de un despertar necesario, el punto de partida de toda representación. Como escribe Piñón Gaytan:

El no sentido de la no existencia, y, el sentido de que algo existe, es el verdadero sentido de la existencia. Es decir, es la conciencia al fin de cuentas la que toma sentido del no sentido de la no existencia. Y si esto es así, la conciencia misma sería un fundamento del ser. No la cosa o el objeto en sí (2014: 205).

\footnotetext{
${ }^{7} \mathrm{La}$ autoconciencia aparece así como el proceso de una «antropología cerrada» (Amengual, 1980: 63); he aquí al Feuerbach exclusivamente subjetivista. «No solo fue callada la alteridad, sino expresamente negada al querer explicar en qué consistía la esencia o el género» (Amengual, 1980: 57). En La esencia del cristianismo, Feuerbach se refiere al papel del otro como mero representante del género: «En el otro alcanzo la conciencia de la humanidad» (Feuerbach, 2013: 203), debido al hecho de que el género se manifiesta de modo distinto en cada individuo (Amengual, 1980: 72).
} 
Además, concebir con límites estas esencias, perfectas y divinas, sería una contradicción. "Finitud y nada son uno y lo mismo» (Feuerbach, 2013: 57). Puesto que la conciencia es la objetivación del ser como esencia, estas determinaciones del género se perciben como infinitas. La infinitud se relaciona con la unidad, lo inconmensurable; mientras que lo finito remite a aquello que puede ser comparado con similares (Feuerbach, 2013: 93). Obviamente, el individuo se representa a sí mismo como un ser limitado, pero solo en la medida en que se contrasta con la infinitud del género. La percepción de lo sublime en la propia esencia es consecuencia necesaria del ser, pues el género es la única referencia posible:

La medida del ser es también la medida del entendimiento. Si el ser es limitado, también lo será el sentimiento y el entendimiento. Pero para un ser limitado no representa el entendimiento limitado ningún límite; está, al contrario, perfectamente feliz y satisfecho consigo mismo; lo siente, lo alaba y enaltece como una fuerza señorial y divina (Feuerbach, 2013: 59).

\subsection{La esencia de la religión}

En Feuerbach, esta autoconciencia del hombre se identifica con la conciencia de Dios, ya que éste no es más que la esencia humana objetivada. Pero el sujeto religioso piensa su propia esencia como un objeto externo, no es consciente de dicha identidad. Por eso, el autor califica la religión de «esencia infantil de la humanidad» (Feuerbach, 2013: 65). Los predicados de Dios son necesariamente asociados a éste por tratarse de cualidades divinas por sí mismas, porque determinan la esencia del género; no son divinas por ser atributos de Dios. De lo que se deriva ${ }^{8}$ que Dios depende del ser humano, en la medida en que existe solo como espejo de éste. También la propia existencia de Dios se percibe como algo sublime, inherente a la esencia del hombre:

Crees que el amor es una propiedad divina porque amas, crees que Dios es un ser sabio y bondadoso porque no conoces en ti mismo nada mejor que

\footnotetext{
${ }^{8}$ Feuerbach argumenta que Dios es una entidad imaginada porque representa la proyección de la esencia humana. Sin embargo, aunque todo conocimiento esté afectado por la proyección de la naturaleza humana, esto no implica necesariamente que Dios no exista. "La orientación de la conciencia humana a un infinito no dice nada determinante sobre la existencia o no existencia de una realidad infinita independiente de la conciencia» (Küng, 1979: 290).
} 
la bondad y el entendimiento, y crees, en fin, que Dios existe, que es sujeto o ser; lo que existe es ser, ya se lo defina como sustancia, persona o de cualquier otra manera; porque tú mismo existes, eres un ser (Feuerbach, 2013: 70).

Feuerbach sostiene que el ejercicio de la teología especulativa genera una imagen distorsionada de Dios como un ser que en la imaginación tiene una naturaleza ajena, diferente de la humana. En su caso, aunque la existencia se sigue percibiendo como una necesidad básica, el resto de predicados divinos se ven como «antropomorfismos» (Feuerbach, 2013: 267), la única manera por la que Dios puede ser pensado por los seres humanos; invirtiendo, por tanto, el razonamiento: el sujeto ya no es verdad en virtud de la verdad inmediata de sus predicados, sino que la existencia de Dios determina la verdad de los predicados. «En un principio crea el hombre la verdad a partir de la existencia y más tarde hace depender la existencia de la verdad» (Feuerbach, 2013: 71). Pero, para la (verdadera) religión, estos predicados divinos expresan realmente la esencia de Dios.

El individuo percibe el mundo exterior como una limitación; las leyes naturales restringen la infinitud de su esencia. La enajenación del ser humano en la religión se fragua como respuesta a su frustración, de modo que cuanto menos tenga, más proyecte en Dios. "Para enriquecer a Dios debe empobrecerse el hombre; para que Dios sea todo, el hombre debe ser nada» (Feuerbach, 2013: 77). Como se verá a continuación, al repasar el desarrollo histórico de la religión que sostiene Feuerbach, este fenómeno cobra mayor importancia en las manifestaciones religiosas que considera más maduras, las monoteístas. $\mathrm{Al}$ menos en el caso del cristianismo, el hombre religioso se basta a sí mismo: «tiene todo en sí, todo en su Dios y, por consiguiente, no tiene necesidad de completarse mediante los otros, los representantes del género, mediante la visión del mundo en general» (Feuerbach, 2013: 205). Es decir, en estos casos, el enriquecimiento de Dios comporta tanto una negación del mundo como un empobrecimiento del hombre; lo que explica conductas como el sacrificio -pues el hombre religioso recibe con creces en Dios aquello de lo que se priva- o el desinterés por la cultura:

El Dios trinitario es un Dios exuberante; por eso se convierte en una necesidad allí donde se prescinde del contenido de la vida real. Cuanto más vacía es la vida, tanto más lleno y completo es Dios. El vaciamiento del mundo real y el enriquecimiento de la divinidad es un solo y mismo acto. Solo el hombre pobre tiene un Dios rico (Feuerbach, 2013: 123). 
La esencia pura, más teórica, de Dios es concebida como otro ser, desligado de los sentimientos. "La esencia divina pura, perfecta, omniperfecta, es la autoconciencia del entendimiento» (Feuerbach, 2013: 86). Feuerbach señala que la percepción de Dios como otro ser no podría suceder si éste no fuera la esencia del hombre, puesto que, de no ser así, el ser humano sería indiferente a los atributos de Dios (Feuerbach, 2013: 85). Éste no puede concebir una razón diferente y superior a la suya, por lo que, cuando la piensa, la objetiva por costumbre ${ }^{9}$ en un ser diferente y abstracto, un ser pensado y liberado de las limitaciones individuales. Es decir, «de Dios en cuanto Dios no se puede formar imagen alguna» (Feuerbach, 2013: 87); toda alusión a un ser personal es objeto de la proyección subjetivista y de la reflexión sobre la religión (de la teología). En definitiva, la enajenación de la razón responde a la necesidad de aliviar la frustración de una capacidad racional no desarrollada plenamente, que en potencia puede ser ilimitada, tal y como se concibe en la esencia del género.

Sin embargo, esta entidad distante no satisface las necesidades inmediatas de la religión. Por un lado, la razón no solo se preocupa del hombre, sino también del mundo (mientras que el contenido de la religión es meramente humano); por otro lado, constituye únicamente «el supremo y último punto de contacto y de unión; es, en cierto modo, el punto matemático de la religión» (Feuerbach, 2013: 95). Lo que realmente cuenta para la religión es la objetivación del ser humano considerado subjetivamente, es decir, en su dimensión emocional. El ser humano persigue su felicidad en la religión, satisfacer sus necesidades. Solo un Dios esencialmente humano conseguiría dar consuelo al hombre. Como individuo, no está en su mano ser omnipotente, pero sí seguir, por ejemplo, los preceptos morales. Además, a la figura del juez, a la evaluación inflexible del cumplimiento de la ley, se contrapone la misericordia del corazón, pues «un ser exclusivamente moral no puede perdonar lo que va contra la ley de la moralidad. Lo que niega la ley es también negado por ella» (Feuerbach, 2013: 99). El corazón -el amor-, por tanto, ha de jugar un papel central en la religión. En el cristianismo, este amor se objetiva en la figura del Hijo. «Dios padre es el yo, Dios hijo es el tú. El yo es el entendimiento, el tú, el amor» (Feuerbach, 2013: 118). Es en base a la supremacía del amor, al amor objetivado con motivo del anhelo de la esencia,

\footnotetext{
${ }^{9}$ «Cuando piensas en Dios, piensas, pues, la razón tal como es en realidad, aunque inmediatamente te representas este ser por medio de la imaginación como diferente de la razón porque estás acostumbrado, como ser sensible, a distinguir continuamente el objeto real (el objeto de la intuición) de su representación» (Feuerbach, 2013: 88).
} 
por lo que Feuerbach considera a Cristo como «el Dios verdadero y real de los cristianos» (Feuerbach, 2013: 193).

\section{Desarrollo histórico de la religión}

«La religión precede siempre a la filosofía» (Feuerbach, 2013: 65), tanto en la historia de la humanidad como en el desarrollo del individuo; acompaña al ser humano desde que es consciente de sí mismo, pues ésta es la autoconciencia del hombre. Responde al impulso psicológico de aliviar de una carencia, las limitaciones del individuo a la luz de la esencia ilimitada del género. Pero, una vez alcanzada la conciencia -alega Feuerbach-, diferentes manifestaciones religiosas se suceden a lo largo de la historia en un proceso evolutivo en que, en general, las nuevas superan a las anteriores. Este fenómeno histórico se identifica explícitamente con la evolución de la cultura, un evolucionismo social que recogerá posteriormente el materialismo histórico. Sin duda, el progresismo ilustrado es una de las raíces de esta concepción y se ve reflejado en el optimismo que proyecta el autor sobre la especie humana ${ }^{10}$. Para Feuerbach, los dioses se conciben como un reflejo de las necesidades humanas en cada época. "Como los deseos de los hombres, así son sus dioses» (Feuerbach, 2008: 104), de modo que se les asocian solo aquellos predicados que se consideran valiosos, buenos para el hombre (Feuerbach, 2013: 72).

Cada religión percibe a las demás como idolatrías; pues su contenido, y no los otros, es verdadero. Desde el punto de vista de la teología, «una religión supera a otra cuando logra desembarazarse de los antropomorfismos todavía presentes en su antecesora» (Uriel, 2010: 53); es decir, cuanto más se elucide la naturaleza de Dios, menor papel jugará la antropología en su determinación. Por el contrario, para Feuerbach, la deriva de este proceso histórico conduce a un conocimiento más claro de la esencia del hombre (Feuerbach, 2013: 65). El nacimiento y desarrollo de las diversas manifestaciones culturales, como la ciencia o el arte, solo es posible en el seno del politeísmo (Feuerbach, 2013: 162). Con el monoteísmo, sobreviene el vaciamiento del mundo, la voluntad ilimitada del ser infinito se ocupa solo del hombre, el único y verdadero objeto de la religión. En la doctrina de la creación se hace depender la existencia del mundo de una

\footnotetext{
10 «La historia de la humanidad no consiste más que en una continua superación de límites, que en un tiempo determinado se consideraban límites de la humanidad, y, por eso, como absolutos e insuperables. Pero el futuro descubre siempre que los supuestos límites del género eran simplemente límites de los particulares» (Feuerbach, 2013: 198).
} 
decisión arbitraria (Feuerbach, 2013: 149); la naturaleza existe entonces para servir al hombre, se reduce a nada, eliminando así los límites que impone a la subjetividad ${ }^{11}$.

Pero originalmente, lejos de sentirse un ser independiente, el ser humano se ve a merced de una naturaleza hostil ${ }^{12}$, por lo que tiende a objetivar el mundo exterior como una existencia al margen de sí mismo. Sin embargo, no concibe la naturaleza como algo completamente extraño, sino que proyecta en ella cualidades propias, la ve como un «ente personal, viviente y sintiente» (Feuerbach, 2008: 52). Aunque el ser humano venere entidades naturales como a dioses, lo hace en tanto en cuanto reconoce en ellas su propia esencia. Además, requieren su atención en la medida en que afectan a sus necesidades, de ahí que Feuerbach insista en que el deseo es la esencia de la religión (Feuerbach, 2008: 60). Mientras en sus acciones se ve limitado -como individuo- por las leyes naturales, en el desear (en el querer) el ser humano es ilimitado; los dioses «hacen efectivas las leyes del corazón humano» (Feuerbach, 2008: 62). Sin embargo, a medida que las propiedades de la naturaleza comienzan a concebirse como cualidades abstractas, se abandona la idea de que Dios ha surgido como respuesta psicológica a la ignorancia sobre el mundo para concebirlo como un ente pensado. Es entonces cuando este Dios abstracto se identifica con la esencia de la razón humana ( $c f$. Feuerbach, 2008: 35). A lo largo de la historia, «el hombre despoja a Dios cada vez más para atribuírselo a sí mismo» (Feuerbach, 2013: 81); a medida que los humanos someten la naturaleza a explicación mediante su entendimiento, cercan más las competencias de Dios. Pero ya se ha visto que el verdadero objeto de la religión no es la naturaleza sino el hombre. El salto de las religiones naturales a las llamadas antropológicas implica la atribución a Dios de cualidades expresamente humanas, como las determinaciones morales, la inteligencia o la voluntad. «Cuando el hombre se yergue con voluntad e inteligencia sobre la naturaleza se vuelve supranaturalista, y entonces también Dios se convierte en un ser supranaturalista» (Feuerbach, 2008: 73). Como consecuencia, el monoteísmo se deriva necesariamente de la infinitud de la esencia humana, pues solo lo infinito no puede ser comparado con entidades de igual rango, es decir, no puede

\footnotetext{
${ }^{11}$ «En el fondo más íntimo de tu alma deseas que no exista ningún mundo, pues donde existe el mundo, hay materia, y donde existe la materia, allí hay presión y choque, espacio y tiempo, límite y necesidad» (Feuerbach, 2013: 157).

${ }^{12}$ En La esencia de la religión, Feuerbach expresa mucho más claramente que el sentimiento de dependencia de la naturaleza representa el impulso inicial de la religión: «Es la naturaleza el primer y originario objeto de la religión, como la historia de todas las religiones y de todos los pueblos prueba abundantemente» (Feuerbach, 2008: 23).
} 
pertenecer a un género. La esencia humana -y por tanto, también Dios- es única. Además, como se ha dicho arriba, con la doctrina de la creación se niega el mundo; la naturaleza ya no impone límites a la subjetividad humana. Los sucesos naturales son ahora mediados por la providencia divina. Sin embargo, cuando se tiene en cuenta la manifestación sensible del mundo, la reflexión sobre la religión introduce elementos especulativos, como las causas segundas ${ }^{13}$, que acaban relegando el papel de la divinidad al de primer motor. Entonces, el racionalista que solo percibe a Dios como encarnación de la esencia de la naturaleza es incapaz de conciliar ambas visiones. «Solo la imaginación resuelve la contradicción en una existencia simultáneamente sensible y no sensible. Solo la imaginación preserva del ateísmo» (Feuerbach, 2013: 248). Por el contrario, para el creyente la naturaleza encuentra, directa o indirectamente, su explicación en Dios. Pero según Feuerbach, éste no hace otra cosa que proyectar sus deseos en los fenómenos naturales - «El hombre convierte a su propia (y a saber, subjetiva) esencia en medida de la naturaleza» (Feuerbach, 2008: 86)-. Dios siente porque el hombre siente. "Cuanto más subjetivo y humano es Dios, tanto más enajena el hombre su propia subjetividad» (Feuerbach, 2013: 81). Para Feuerbach, el cristianismo constituye, efectivamente, la culminación de este proceso histórico, porque expresa de un modo mucho más claro la verdadera esencia de la religión -pues contiene la figura del Hijo, que es el amor objetivado-:

En Cristo se realiza el último deseo de la religión, se resuelve el misterio del sentimiento religioso -resuelto, sin embargo, en el lenguaje figurado propio de la religión-, pues lo que Dios es en esencia, se ha manifestado en Cristo. A este respecto se puede llamar a la religión cristiana, con toda razón, absoluta y perfecta. Que Dios, que no es más que la esencia del hombre, sea también realizado en cuanto tal, y que como hombre llegue a ser objeto para la conciencia, constituye el fin de la religión (Feuerbach, 2013: 190-191).

La virtud del cristianismo -lo que lo diferencia de las demás religioneses que en él «la imaginación está limitada por las necesidades del corazón» (Feuerbach, 2013: 194). Además, el Dios cristiano aspira a la universalidad, recoge plenamente la esencia humana, mientras que otras religiones-como la griega o la judía- exhiben un sesgo local en la medida en que sus dioses expresan la esencia específica de sus pueblos ( $c f$. Uriel, 2010: 57). Sin embargo, no se debe perder de vista que cuando Feuerbach se refiere al cristianismo, lo hace

\footnotetext{
13 «La causa segunda es la capitulación del entendimiento incrédulo ante el corazón todavía creyente» (Feuerbach, 2013: 235).
} 
en relación con sus orígenes ${ }^{14}$. Se remonta a un tiempo en que la teología no deformara aún su verdadera esencia como resultado de la reflexión especulativa. La teología profundiza en la esencia del entendimiento, es decir, en Dios como su objetivación en un ser abstracto, otorgándole personalidad (Feuerbach, 2013: 267) y separando así al hombre de lo que fuera su propia esencia:

Cuando la religión crece en años, (...) cuando la religión se convierte en teología, entonces la separación de Dios y del hombre, primitivamente involuntaria e inocente, se convierte en una diferenciación deliberada, erudita que no tiene otro fin más que la eliminación de la conciencia de esta unidad introducida ya en ella (Feuerbach, 2013: 243).

Puesto que solo un ser plenamente humano puede experimentar sentimientos humanos, Feuerbach alega que esta fijación por la personalidad y, en general, la esencia de Dios niega el propio contenido de la religión. Además, las manifestaciones de este ser distinto del hombre y de la naturaleza solo pueden percibirse con ayuda de la imaginación -a través de la creencia en milagros y de la revelación- y sus mandamientos como normas externas y arbitrarias, ajenas a las necesidades del corazón. La contradicción entre la fe y el amor surge entonces del desacuerdo entre la representación que prescribe la fe y la percepción de los sentidos. O dicho más claramente: «Feuerbach acusa al sujeto religioso de llevar una existencia alienante» (García-Valdecasas y Belmonte, 2018: 402).

El cristianismo adulterado, por tanto, no corresponde a las necesidades humanas. Una vez alcanzada la situación de mayor abstracción teológica, es «misión de la filosofía apropiarse del cristianismo» (Uriel, 2010: 55) para que, en el futuro, la antropología pueda expresarse en sus propios términos, abandonando la mascarada de la teología. Feuerbach hace ver que el reconocimiento de que la verdadera esencia de la religión es la conciencia del género constituye un momento crítico y necesario en la historia de la humanidad, el siguiente estadio en la evolución de la religión como proceso de autoconocimiento cada vez más profundo. La eliminación de la escisión humana, para lo cual se hace necesario colocar al hombre como objeto central de la religión:

\footnotetext{
${ }^{14}$ Gabriel Amengual califica de hermeneuta a Feuerbach en la medida en que éste se propone descifrar el contenido verdadero de la religión a pesar de las falsas apariencias. El significado se capta en el origen de la religión, de ahí que califique su metodología de genético-crítica (Amengual, 1980: 43-46).
} 
La unidad de la esencia humana consigo misma solo llegará si abandonamos la idea de una filosofía especial de la religión o una teología diferente de la psicología o la antropología. Y reconocemos, por el contrario, la teología misma como antropología (Feuerbach, 2013: 275).

Retrospectivamente, la historia del cristianismo -en este esquema- desemboca en el reconocimiento de la teología como antropología (García-Valdecasas y Belmonte, 2018: 400). En la medida en que las necesidades humanas son cubiertas por el propio ser humano, la prevalencia de elementos sobrenaturales se hace innecesaria; lo cual no solo se aplica al conocimiento del mundo exterior, sino también a su propia subjetividad (Bentue, 1971: 52).

\section{El amor como superación del cristianismo}

En el pensamiento de Feuerbach, y en contra de lo que sugiere la teología, el amor de Dios es el amor del hombre. La diferencia entre cualidades divinas y humanas no es cualitativa, sino solo cuantitativa; puesto que Dios no es más que la esencia del hombre, ambos comparten las mismas pero en la divinidad se subliman, se expresan más allá de los límites del individuo, ya que «Dios es todo lo que desea y exige el corazón» (Feuerbach, 2013: 261). El amor promovido por la fe no es amor genuino, pues desde el momento en que la fe condena a aquellos que no la profesan, solo los cristianos pueden beneficiarse de él (Feuerbach, 2013: 296). La fe, tal y como es concebida por Feuerbach, niega la razón allí donde sus preceptos entran en conflicto con la experiencia sensible. Pero, además, tampoco inspira la moralidad del ser humano; incluso la contraviene, en tanto en cuanto entra en conflicto con el corazón. El ser humano de fe se mueve llevado por el espíritu del sacrificio, «hace el bien no por amor del bien mismo, ni del hombre, sino por amor de Dios; por gratitud hacia Dios que ha hecho todo por él» (Feuerbach, 2013: 304). Se trata, en último término, de un amor interesado. Lo cual no implica que el cristianismo se haya desarrollado con independencia del amor genuino. Como se ha dicho más arriba, Cristo constituye la objetivación del amor universal, la encarnación del Dios sintiente ${ }^{15}$. Ha sido la reflexión sobre la religión la que, con los años, ha enturbiado su verdadera esencia, reemplazando su contenido humano por un Dios extraño:

\footnotetext{
15 «Para Feuerbach, la Encarnación es el misterio cristiano más importante por el hecho de que se trata del mito fundamental de la realidad humana: el amor del hombre por el hombre» (Bentue, 1971: 52).
} 
El cristianismo sanciona al mismo tiempo los actos que proceden del amor y los actos que proceden de la fe sin amor. Si el cristianismo hubiera convertido el amor en ley, tendrían razón sus seguidores, no se le podría hacer responsable de las atrocidades de la historia de la religión cristiana; si hubiera convertido la fe en ley, los reproches de los no creyentes serían verdaderos incondicionalmente y sin limitación. El cristianismo no ha franqueado el amor; no se ha elevado hasta la altura de concebir el amor como un absoluto. No ha tenido esta libertad ni ha podido tenerla, porque es una religión; el amor es sometido a la dominación de la fe (Feuerbach, 2013: 305).

Si "Dios es amor", si el amor es un predicado de Dios, aún hay margen para que el sujeto sea más que el predicado. Feuerbach plantea invertir la proposición para convertirla en "el amor es Dios", renunciando a la personalidad de Dios y eliminando así la diferencia entre sujeto y predicado. De lo contrario, «el amor no llena únicamente mi espíritu; dejo un lugar abierto para mi falta de amor» (Feuerbach, 2013: 305). La esencia del amor ${ }^{16}$ no conoce límites, es universal; es el corazón satisfecho de sí mismo. Además, el amor ha de ser inmediato, ha de surgir sin intermediarios. En cierto modo, las relaciones con los otros pasan a engrosar el grupo de las manifestaciones religiosas. «El hombre es objeto del amor porque es un ser que es fin para sí mismo» (Feuerbach, 2013: 309). Por tanto, la elevación del amor conlleva el reconocimiento de que el objeto de la religión no es otra cosa que la esencia humana; y dicho reconocimiento se impone como una necesidad:

El necesario momento crítico de la historia es esta confesión y declaracíon pública de que la conciencia de Dios es la conciencia del género, de que el hombre debe y puede elevarse sobre los límites de su individualidad o personalidad, pero no sobre las leyes que son determinaciones de la esencia de su género, de que el hombre solo puede pensar, presentar, representar, sentir, creer, querer, amar y venerar la esencia absoluta y divina como esencia humana (Feuerbach, 2013: 311).

Con la alusión a las leyes que presentan determinaciones -no limitaciones-a la esencia humana, Feuerbach adelanta la devolución del ser humano a su lugar

\footnotetext{
16 «El amor es la existencia subjetiva del género, así como la razón es la existencia objetiva del mismo» (Feuerbach, 2013: 309). Solo en el género se da la complementariedad que sirve de base a las relaciones humanas, el amor «es en el individuo el autosentimiento de la perfección e infinitud del género» (Amengual, 1980: 73).
} 
en la naturaleza. La crítica de Stirner -para quien Feuerbach, lejos de conseguir su pretendida inversión de Hegel, lo único que logra es sustituir un Dios por otro (Stirner, 2018: 64) - afectó sin duda a la evolución de sus planteamientos ( $c f$. Cabada, 1975: 33-34). En concreto, a la eliminación de los elementos metafísicos presentes en la idea de género recogida en La esencia del cristianismo. También Marx, quien profesaba una reconocida admiración por Feuerbach, rechazó la concepción abstracta del género por distante de la realidad práctica del hombre $^{17}$ ( $c f$. Marx y Engels, 1974: 667). Si bien Feuerbach cree que eliminar la idea de género dejaría un vacío que los seres humanos volverían a llenar con Dios, sus predicados dejan de ser divinos para concebirse como naturales y humanos (Cabada, 1975: 108). La nueva concepción se explicita en 1943 en los Principios de la filosofía del futuro, donde lo sensible (el no-pensamiento frente al pensamiento, que alude exclusivamente a uno mismo) conduce necesariamente a la reciprocidad ( $c f$. Arroyo, 2006: 212-215): «Únicamente los seres sensibles actúan unos en otros. Yo soy yo -para mí- y, al propio tiempo, soy tú -para otro-» (Feuerbach, 1984: 118). Se consuma así el espíritu de su no-filosofía, para la cual el objeto de estudio es el ser humano concreto y material, y no el concepto puramente lógico concebido mediante proposiciones dadas a priori propio de la filosofía especulativa ( $c f$. López, 2018: 325). «La esencia del hombre se da únicamente en la comunidad, en la unidad del hombre con el hombre; unidad que, con todo, se basa solo en la realidad de la distinción entre yo y tú» (Feuerbach, 1984: 138). Ahora «el amor es, objetiva y subjetivamente, el criterio del ser, de la verdad y de la realidad. Donde no hay amor no hay verdad. Solamente es algo quien ama algo» (Cabada, 1975: 43). La antropología cerrada cede el paso al precedente de una antropología dialógica posteriormente desarrollada por Martin Buber, a partir de la cual se propone un nuevo modo de acceso a la realidad, ya no persiguiendo el pensamiento objetivo que refleje lo real, sino a través del diálogo entre sujetos: la realidad se muestra a los demás, se re-conoce (cf. Arroyo, 2007).

\section{Conclusiones}

El origen de la religión, según Feuerbach, es el origen de la conciencia. El ser humano es consciente de sí mismo en tanto en cuanto tiene como objeto

\footnotetext{
${ }^{17}$ Aunque, en opinión de Cabada (1975: 37), el problema no es tanto que Feuerbach sea demasiado abstracto como que no da suficiente relevancia a los problemas socioeconómicos. Para Marx, el Estado y la Sociedad producen religión, que constrituye «el opio del pueblo» (Marx en Hegel, 1968: 7).
} 
su propio género. Concibe la esencia de la especie en base a aquellos atributos que percibe en sí mismo pero objetiva como cualidades divinas. La objetivación del género en un ser diferente constituye la verdad última de la religión. En un principio, para el autor, conocer la realidad es un monólogo autorreferencial; sin embargo, la evolución de su pensamiento conduce a una antropología de la sensibilidad (Arroyo, 2006: 212), en la cual el género se construye en base a la socialización.

Desde una perspectiva histórica, Feuerbach presenta las diferentes manifestaciones religiosas como estadios de un proceso en que el ser humano adquiere un conocimiento cada vez más profundo de su propia esencia. La primera actitud religiosa se concibe como "la autoconciencia primaria e indirecta del hombre» (Feuerbach, 2013: 65). Después, «la revelación de Dios avanza paralelamente al desarrollo del género humano (...) pues la revelación de Dios no es más que la revelación, el autodespliegue de la esencia humana» (Feuerbach, 2013: 165). Un ejemplo de este proceso, explicitado en La esencia del cristianismo, es precisamente la concepción de la naturaleza. Si bien desde el politeísmo pagano se fomentaba una actitud contemplativa y de admiración hacia ella, desde las religiones monoteístas se procedió a negarla ante la prioridad de las necesidades subjetivistas del ser humano. Feuerbach concibe el cristianismo como la forma más elevada de religión, pues la que considera su figura más importante, Cristo, encarna el amor universal, es la objetivación del corazón humano. Sin embargo, a medida que el cristianismo es objeto de reflexión teológica, se deforma su verdadera esencia, ya que dicha actividad tiende a separar al ser humano y a Dios -lo que otrora fuera uno, lo que constituye el verdadero misterio encerrado en la religión- asociando a éste último una naturaleza y personalidad distanciadas.

Como resultado de la contradicción entre la fe y el testimonio de los sentidos, entre la fe y las necesidades del corazón, los seres humanos están abocados a una vida alienante. Una vez alcanzada en el cristianismo la premisa "Dios es amor", se agota el recorrido que ofrece el subterfugio de la religión hacia un autoconocimiento más profundo. Para avanzar un paso más en el proceso, se hace necesaria la abolición de la escisión humana a través del reconocimiento de la teología como antropología. Adoptando como premisa "el amor es Dios", el ser humano trazaría su vida conforme a las necesidades del corazón -pues el amor es su propia subjetividad objetivada- sin verse obligado a mantener incoherencias con la experiencia sensible. «El hombre de Feuerbach, en cuanto humano, se realiza 
con otros y no está en conflicto con el mundo ni le sobrecoge un camino suprahumano (...) se realiza en la humanidad y no en el espíritu» (López, 2018: 341).

\section{Agradecimientos}

El autor agradece la labor docente de Sonia Ester Rodríguez García en la asignatura Religión y Filosofía del Máster Universitario de Filosofía Teórica y Práctica de la UNED. La actividad desarrollada durante el curso constituyó la semilla de este artículo.

\section{Bibliografía}

Arroyo Arrayás, L. M. (2006). “'Humanismo y cristianismo'. El humanismo ateo”. Thémata. Revista de Filosofia, 36, 207-221.

- (2007). "La antropología dialógica en la historia de la filosofía". Thémata. Revista de Filosofia, 39, 301-307.

Amengual, G. (1980). Crítica de la religión y antropología en Ludwig Feuerbach. La reducción antropológica de la teología como paso del idealismo al materialismo. Barcelona: Editorial Laia.

Bentue, A. (1971). "Nietzsche, Feuerbach y el 'cristianismo no religioso". Teología y Vida, 12, 47-57.

Cabada Castro, M. (1975). El humanismo premarxista de L. Feuerbach. Madrid: La Editorial Católica.

- (1980). Feuerbach y Kant. Dos actitudes antropológicas. Madrid: Publicaciones de la Universidad Pontificia Comillas de Madrid.

- (2010). "La autorrealización o liberación humana como crítica de la religión en Feuerbach”. En M. Fraijó (ed.), Filosofía de la religión. Estudios y textos. Madrid: Editorial Trotta, 291-316.

Feuerbach, L. (1984). "Principios de la filosofía del futuro". En J. M. Quintana Cabanas (ed.), Principios de la filosofía del futuro y otros escritos, Barcelona: Editorial Humanitas, 70-140.

— (2008). La esencia de la religión. Madrid: Editorial Páginas de Espuma. 
— (2013). La esencia del cristianismo. Madrid: Editorial Trotta.

García-Valdecasas, J. I., y Belmonte García, O. (2018). "La religión del amor: Feuerbach y los filósofos del diálogo". Anales del Seminario de Historia de la Filosofía, 35(2), 395-414. DOI: 10.5209/ASHF.59661

Gil Martínez, J. (2016). "Recepción y crítica del pensamiento filosófico de Ludwig Feuerbach". Kriterion: Revista de Filosofia, 57(134), 505-524. DOI: 10.1590/0100-512x2016n13408jgm

Hegel, G. W. F. (1968). Filosofia del Derecho. Buenos Aires: Editorial Claridad.

KüNG, H. (1979). ¿Existe Dios? Respuesta al problema de Dios en nuestro tiempo. Madrid: Ediciones Cristiandad.

López Bolívar, M. C. (2018). "Feuerbach: El giro antropológico de la teología”. Perseitas, 6(2), 319-351. DOI: 10.21501/23461780.2844

Marx, K. y Engels, F. (1974). La ideología alemana. Crítica que la novisima filosofía alemana en las personas de sus representantes Feuerbach, B. Bauer y Stirner y del socialismo alemán en la de sus diferentes profetas. Barcelona: Ediciones Grijalbo.

Piñón Gaytan, J. F. (2014). "Feuerbach: 'Dios como esencia del hombre (Homo homini Deus)"'. Andamios. Revista de Investigación Social, 11(24), 191-214.

Stirner, M. (2018). El Único y su propiedad. Buenos Aires: Libros de Anarres.

Uriel Rodríguez, P. (2010). "Feuerbach y Nietzsche: la reducción antropológica de la religión y el sentido del cristianismo". Instantes y Azares, 8, 47-61.

Recibido: $14 / 3 / 2019$

Aceptado: 2/6/2019

Este trabajo se encuentra bajo una licencia de Creative Commons ReconocimientoNoComercial-SinObraDerivada 4.0 